\title{
Formaldehyde Vapor Concentration in Electronic Cigarettes and Health Complaints of Electronic Cigarettes Smokers in Indonesia
}

\author{
Kusuma S. Lestari $\mathbb{D}^{1},{ }^{1}$ Mika Vernicia Humairo ${ }^{(D)},{ }^{2}$ and Ukik Agustina ${ }^{2}$ \\ ${ }^{1}$ Department of Environmental Health, Faculty of Public Health, Universitas Airlangga, Surabaya 60115, Indonesia \\ ${ }^{2}$ Faculty of Public Health, Universitas Airlangga, Surabaya 60115, Indonesia \\ Correspondence should be addressed to Kusuma S. Lestari; kusumalestari@fkm.unair.ac.id
}

Received 28 February 2018; Accepted 5 June 2018; Published 11 July 2018

Academic Editor: Sina Dobaradaran

Copyright (C) 2018 Kusuma S. Lestari et al. This is an open access article distributed under the Creative Commons Attribution License, which permits unrestricted use, distribution, and reproduction in any medium, provided the original work is properly cited.

\begin{abstract}
Electronic cigarettes regulation in Indonesia has not been set yet. In the last 4 years the electronic cigarettes have been widely distributed and used in Indonesia. Electronic cigarettes contain nicotine, propylene glycol, glycerol, liquid flavors, etc. All ingredients produce vapor when heated. Vapor and particles from electronic cigarettes affect the human health. Formaldehyde is known as a product of propylene glycol and glycerol vapor degradation. Formaldehyde is one of the chemical agents categorized as carcinogen. The aim of the research was to analyze the identification of formaldehyde vapor concentration and health complaint of electronic cigarettes smoker. The research was conducted in Surabaya city, Indonesia, from October 2015 to December 2016. The research used cross-sectional approach. Sample was obtained by purposive sampling that fulfilled samples inclusion criteria. The variables were the onset of smoking electronic cigarettes, smoking frequency of electronic cigarettes, formaldehyde vapor concentration, cotinine urine, and health complaint of electronic cigarettes smoker. The result showed that formaldehyde concentration in six vapors varied while cotinine urine mostly was positive. It is suggested to educate people about hazard of electronic cigarettes and to conduct further research to identify chemical agent in electronic cigarettes.
\end{abstract}

\section{Background/Objectives and Goals}

Electronic cigarette was developed in the beginning in 2004 as an alternative of nicotine replacement therapy in liquid to reduce tobacco consumption [1]. Electronic Nicotine Delivery System (ENDS) is a device to convert chemical agent to vapor and divert it from lungs. The device consists of rechargeable batteries, electronic regulator, and a container of liquid that will be evaporated [2].

Electronic cigarettes are produced by industries in order to stop smoking or as an alternative of tobacco cigarettes because it does not produce smoke. It is added more than 8,000 flavorings and one of them is nicotine. Nicotine is addictive to a person who wants to stop smoking, especially young people. According to South-East Asia Region (SEARO) (2013) the total of electronic cigarette smokers has doubled in adults from 2008 to 2012 [3]. Centers for Disease Control and Prevention (CDC) researchers, Food and Drug
Administration (FDA), and Georgia State University stated that the number of teens who had never smoked but use electronic cigarette increased three times during the year 2011-2013. The number of teens who do not smoke conventional cigarettes but use electronic cigarettes increased from 79,000 in the year 2011 and became 263,000 in 2013 [4]. In 2013 the use of electronic cigarettes was doubled among US middle and high school students during 2011-2012. Moreover, in 2012, about 160,000 students who had not been using conventional cigarettes were using electronic cigarettes [5]. Intention to smoke conventional cigarettes was $43.9 \%$ among electronic cigarettes smoker and $21.5 \%$ among non-electronic cigarettes smoker [4]. In UK, in 2013, about 1.3 million smokers used electronic cigarettes while in previous year there were about 700,000. Several studies in US showed that about $38 \%$ smokers have used electronic cigarettes in order to quit smoking [5]. 
Electronic cigarette was first introduced in China in 2003 and was distributed online afterwards [2]. Electronic cigarette distribution extends to several countries and Indonesia is one of them. In some countries the regulations related to the distribution of electronic cigarettes are different: they are considered as illegal goods in some, are allowed (no regulation), and are allowed under certain conditions and have been organized by the Ministry of Health as a registered medicine (not freely traded) in others. In Indonesia, the regulations related to the distribution and use of electronic cigarette have not been set yet. Indonesia Food and Drug Agency stated that electronic cigarettes that have been distributed in some cities are illegal and unsafe products. This product has not been tested clinically; therefore it is dangerous. World Health Organization (2014) stated that products containing nicotine in various forms such as electronic cigarette are unsafe to use which can cause addiction to nicotine so World Health Organization (WHO) recommends banning the distribution [1].

Electronic cigarette contains nicotine, propylene glycol, and some other substances. During vaping the gas phase 1.2propanediol, glycerin, and nicotine were found. The concentration of Polycyclic Aromatic Hydrocarbons (PAH) in indoor air increased by $20 \%$ to $147 \mathrm{ng} / \mathrm{m}^{3}$ and aluminum showed a 2.4-fold increase; particle number concentration (PNC) ranged from 48,620 to 88,386 particles $/ \mathrm{cm}^{3}$ [6]. Pollutant is containing Volatile Organic Compounds (VOCs), carbonyls, PAH, nicotine, Tobacco-specific nitrosamine (TSNAs), and glycols [7]. At least 10 chemicals identified in mainstream (MS) and secondhand (SS) Electronic Smoking Device (ESD) aerosols are on California's Proposition including acetaldehyde (MS), benzene (SS), cadmium (MS), formaldehyde (MS, SS), isoprene (SS), lead (MS), nickel (MS), nicotine (MS, SS), N-nitrosonornicotine (MS, SS), and toluene (MS, SS) [8].

Health risks from electronic cigarette smoking are derived from the ability of vapors that contain fine particles of the nicotine and other harmful substances to enter into lungs. Nicotine increases the adrenaline, increasing blood pressure, and pulse. Propylene glycol at high levels causes irritation if inhaled [2]. Vapor of electronic cigarette contains some toxic substances and levels of toxic substances 9-450 times lower than cigarette smoke [9]. Another substance in electronic cigarette is formaldehyde which is categorized as a carcinogen. Formaldehyde is known as a result of the degradation products of propylene glycol and glycerol during the process of evaporation and incomplete combustion. In many samples of the particulate matter (i.e., the aerosol) in electronic cigarettes, more than $2 \%$ of the total solvent molecules have converted to formaldehyde-releasing agents, reaching concentrations higher than concentrations of nicotine. This occurs because of propylene glycol and glycerol is heated using oxygen [10]. When propylene glycol is heated it may change the chemical composition and produce propylene oxide in a little amount which is known as carcinogen [11]. In the past four years, the electronic cigarette's community in Surabaya city has been developed. The aim of research was to analyze the identification of formaldehyde vapor concentration and health complaint of electronic cigarettes smoker.

\section{Materials and Methods}

The research used cross-sectional approach. The research was conducted in Surabaya city, Indonesia, from October 2015 to December 2016. The sample consisted of active electronic cigarettes smokers who have been smoking for at least 2 months as members of electronic cigarette community. The inclusion criteria were being above 18 years. The sample consisted of 20 respondents and it was obtained by purposive sampling that fulfilled samples inclusion criteria.

The dependent variables were health complaints of active electronic cigarettes smoker. The independent variables were the onset of smoking electronic cigarettes, smoking frequency of electronic cigarettes, reasoning of using electronic cigarettes, being a person who asked to use electronic cigarettes, opinion on policy of electronic cigarette in Indonesia, cotinine urine, and formaldehyde vapor concentration. Data was obtained by interviews, questionnaire, and measurement.

Health complaints were obtained by interviews using questionnaire. They were subjective feelings during smoking electronic cigarettes such as irritation in nose, eye, and throat. Nose irritation included itchy nose, uncomfortable smell, and sneezing. Eye irritation included watery eye, sore eye, and reddish eye. Upper airway irritation included sore throat, dry throat, cough, and asphyxia. The onset of smoking, smoking frequency of electronic cigarettes, reasoning of using electronic cigarettes, being a person who asked to use electronic cigarettes, and opinion on policy of electronic cigarette in Indonesia were obtained by interviews using questionnaire. The onset of smoking identifies the age when the person started smoking electronic cigarettes. The smoking frequency of electronic cigarettes identifies the frequency of smoking electronic cigarettes in a day.

Formaldehyde was measured in media which did not contain formaldehyde material and was made from glass. Glass container was filled by electronic cigarette vapor by smoker. There was three smokers and each smoker was using two electronic cigarettes brands. In the first minute the smoker inhaled and exhaled into glass container. In the second and the third minutes the smoker took a break. They continued to the fourth minute to inhale and exhale and in the fifth and the sixth minutes they took a break again. This was repeated until the 60 th minute. The formaldehyde device was using Airchek Sampler put inside glass container before the measurement was done. The measurement of electronic cigarettes brand was done to identify the formaldehyde concentration vapor in six brands of electronic cigarettes that are liquid local 90(VG)/10(PG), liquid USA 60(PG)/40(VG), liquid Malay 60(PG)/40(VG), liquid local 60(PG)/40(VG), liquid Malay $30(\mathrm{PG}) / 70(\mathrm{VG})$, and liquid USA $70(\mathrm{PG}) / 30(\mathrm{VG})$. Before measuring six vapors, in the beginning formaldehyde concentration was measured in empty glass container as a control. Formaldehyde vapor concentration was analyzed at Occupational Safety and Health Laboratory. The method used colorimeter, the principle of which is formaldehyde reacting with chromotropic acid-sulfuric solution to form a purple monocationic chromogen and being read by spectrophotometer at $580 \mathrm{~nm}$. Sensitivity is from $0.1 \mu \mathrm{g} / \mathrm{mL}$ to 
TABLE 1: Characteristics of cigarette smoker in personal vapor community in Surabaya city in 2016.

\begin{tabular}{lc}
\hline Age (years) & Percentage (\%) \\
\hline 18 & 12.0 \\
19 & 20.0 \\
20 & 16.0 \\
\hline Age (years) & Percentage (\%) \\
\hline 21 & 8.0 \\
22 & 8.0 \\
23 & 8.0 \\
24 & 12.0 \\
25 & 12.0 \\
\hline
\end{tabular}

Source: primary data.

TABLE 2: Education and occupation of electronic cigarettes smoker in personal vapor community in Surabaya city in 2016.

\begin{tabular}{lc}
\hline Education & Percentage (\%) \\
\hline Bachelor & 12.0 \\
High School & 80.0 \\
Master & 8.0 \\
\hline Occupation & Percentage (\%) \\
\hline Athlete & 4.0 \\
College student & 44.0 \\
Entrepreneur & 8.0 \\
Labor & 4.0 \\
Private worker & 36.0 \\
Unemployment & 4.0 \\
\hline
\end{tabular}

Source: primary data.

$2.0 \mu \mathrm{g} / \mathrm{mL}$ of formaldehyde which can be measured in the color developed solution. The procedure of formaldehyde concentration measurement with colorimetric method was sampling formaldehyde from vapor with ambient air at a rate of $1 \mathrm{~L} / \mathrm{min}$ for 24 hours, adding $4-\mathrm{mL}$ aliquot from each of the sampling solutions into glass stoppered test tubes, adding $0.1 \mathrm{~mL}$ of $1 \%$ chromotropic acid reagent to the solution and mix, adding slowly and cautiously $6 \mathrm{~mL}$ of concentrated sulfuric acid, and reading at $580 \mathrm{~nm}$ in a suitable spectrophotometer using a $1-\mathrm{cm}$ cell.

Cotinine urine was measured by COT rapid test cassette (urine) $(200 \mathrm{ng} / \mathrm{ml})$. The subject should sign and date the consent form. The interviewer team also has to sign and date the consent form. This research was approved by Faculty of Public Health Universitas Airlangga's committee ethical board.

\section{Result and Discussion}

3.1. Characteristics of Electric Cigarette Smoker. Characteristics of electronic cigarette smoker identified age and sex (Table 1). Most of them were 19 years old (20.0\%). Table 2 showed that $80.0 \%$ finished high school and $44.0 \%$ were college students.
TABLE 3: Onset of using electronic cigarettes among personal vapor community in Surabaya city in 2016.

\begin{tabular}{lc}
\hline Year & Percentage (\%) \\
\hline 2008 & 4.0 \\
2012 & 4.0 \\
2013 & 4.0 \\
2014 & 28.0 \\
2015 & 36.0 \\
2016 & 24.0 \\
\hline
\end{tabular}

Source: primary data.

TABLE 4: Frequency of daily smoking of electronic cigarettes in personal vapor community in Surabaya city in 2016.

\begin{tabular}{lc}
\hline Frequency (time) & Percentage (\%) \\
\hline 1 & 8.0 \\
2 & 12.0 \\
3 & 12.0 \\
4 & 8.0 \\
5 & 4.0 \\
6 & 8.0 \\
11 & 4.0 \\
12 & 4.0 \\
20 & 4.0 \\
Unclassified & 36.0 \\
\hline Source: primary data. &
\end{tabular}

TABLE 5: Reasoning of smoking electronic cigarettes in personal vapor community in Surabaya city in 2016.

\begin{tabular}{lc}
\hline Reasoning & Percentage (\%) \\
\hline Harmless & 4.0 \\
Liking & 4.0 \\
To quit smoking conventional cigarettes & 36.0 \\
To reduce smoking conventional cigarettes & 12.0 \\
To taste the flavor & 20.0 \\
To try & 24.0 \\
\hline
\end{tabular}

Source: primary data.

Table 3 described that mostly they started using electronic cigarettes in 2015 (36.0\%), while frequency of using electronic cigarettes (Table 4) was twice a day and three times a day $(12.0 \%)$. Some respondents used electronic cigarettes unregularly, only 3 times a week, when there was available liquid, if there was a friend, or when they were stressed.

Person who asked respondents to use electronic cigarettes mostly were their friends and some respondents' initiative came from their own will.

Mostly, reasoning of smoking electronic cigarettes (Table 5) was to quit smoking conventional cigarettes $(36.0 \%)$ and to try $(24.0 \%)$.

3.2. Formaldehyde Vapor Concentration in Electronic Cigarettes. Formaldehyde was measured in glass container. The 
TABLE 6: Formaldehyde vapor concentration in electronic cigarettes.

\begin{tabular}{lc}
\hline Measurement & Formaldehyde Concentration (ppm) \\
\hline Control & 0.0009 \\
1 & 0.1490 \\
2 & 0.0658 \\
3 & 0.0767 \\
\hline Measurement & Formaldehyde Concentration (ppm) \\
\hline 4 & 0.0709 \\
5 & 0.0345 \\
6 & 0.1419 \\
\hline
\end{tabular}

Source: primary data.

measurement of electronic cigarettes brand was done to identify the formaldehyde concentration vapor in each brand of electronic cigarettes. The duration of formaldehyde measurement was 60 minutes within the same smoking period in each measurement. The ingredients of vapor were glycerin (VG), propylene glycol (PG), and nicotine in different amounts. First vapor (local vapor) contained $90 \%$ glycerin and $10 \%$ propylene glycol. Vapor 2 (USA) contained $60 \%$ glycerin and $40 \%$ propylene glycol. Vapor 3 (Malay) contained 60\% glycerin and $40 \%$ propylene glycol. Vapor 4 (local vapor) contained $60 \%$ glycerin and $40 \%$ propylene glycol. Vapor 5 (Malay) contained 30\% glycerin and 70\% propylene glycol. Vapor 6 contained $70 \%$ glycerin and 30\% propylene glycol in electronic cigarettes.

Electronic cigarette generates carbonyl compound in the electronic cigarette smoke mist from the oxidation of liquids such as glycerol and glycols. These liquids are oxidized to formaldehyde, acetaldehyde, acrolein, glyoxal, and methylglyoxal [12]. Thermodegradation of glycerol can lead to various carbonyls, such as acrolein and formaldehyde [13, 14]. Formaldehyde, acetaldehyde, and propionaldehyde were found at room temperature. It showed that at temperature of $150^{\circ} \mathrm{C}$ the level of formaldehyde and acetaldehyde was higher 20 -fold than ambient temperature [15].

Formaldehyde concentration in control was $0.0009 \mathrm{ppm}$. Six vapors contained formaldehyde in variation concentration with the highest in vapor 1 and vapor 6 (Table 6). Vapor 1 contained 90\% glycerin and vapor 6 contained $70 \%$ glycerin. Formaldehyde concentration of vapor 5 was 0.0345 which contained propylene glycol $70 \%$. Several studies showed that voltage of electronic cigarette had contributed to difference of formaldehyde concentration. At low voltage $(3.3 \mathrm{~V})$ formaldehyde was not detected while it was detected at high voltage $(5.0 \mathrm{~V})$ [10]. Propylene glycol was approved by FDA for being applied in some products, but it is not approved for inhalation. When propylene glycol is heated this may change the chemical composition and it may produce propylene oxide in a little amount which is known as carcinogen [11]. Several studies on electronic cigarettes showed an increase formaldehyde concentration $[6,9,12]$. Recent study compared metal concentration in dispenser, tank, and aerosol of electronic cigarettes. It identified and measured aerosol metal concentration due to its toxicity in human health. There were 5 metals measured such as $\mathrm{Ni}, \mathrm{Cr}, \mathrm{Mn}, \mathrm{Pb}$, and
TABLE 7: Health complaint of electronic cigarettes smoker in personal vapor community in Surabaya city in 2016.

\begin{tabular}{lc}
\hline Health Complaint & \\
\hline Eye Irritation & Yes (\%) \\
\hline Reddish eye & $0(0.0)$ \\
Sore eye & $1(5.0)$ \\
Watery eye & $1(5.0)$ \\
\hline Nose Irritation & Yes (\%) \\
\hline Itchy nose & $3(15.0)$ \\
Sneezing & $4(20.0)$ \\
Uncomforted smell & $1(5.0)$ \\
\hline Upper airway irritation & Yes (\%) \\
\hline Asphyxia & $1(5.0)$ \\
Cough & $5(25.0)$ \\
Dried throat & $13(65.0)$ \\
Sore throat & $2(10.0)$ \\
\hline
\end{tabular}

Source: primary data.

As. $\mathrm{Ni}(57.0 \%)$ and $\mathrm{Mn}(14.0 \%)$ concentration in electronic cigarettes exceeded the daily chronic minimum risk level of the Agency for Toxic Substances Disease Registry (median $4.44 \times 10^{-4} \mathrm{mg} / \mathrm{m}^{3}$ and $1.97 \times 10^{-5} \mathrm{mg} / \mathrm{m}^{3}$, respectively), while $\mathrm{Pb}(48.0 \%)$ concentration in electronic cigarettes exceeded the US EPA National Ambient Air Quality (median $1.06 \mathrm{x}$ $10^{-4} \mathrm{mg} / \mathrm{m}^{3}$ ). Concentration in aerosol was 25 times higher than in refilling dispenser $(\mathrm{Pb}$ and $\mathrm{Zn})$ and was 6 times higher than in the dispenser $(\mathrm{Cr}, \mathrm{Ni}$, and $\mathrm{Sn})$. Mn concentration in aerosol was 1.93 times higher than in dispenser. $\mathrm{Al}$, $\mathrm{Cd}$, and $\mathrm{Sb}$ concentration was between 1.60 and 3.58 times higher than the dispenser [16]. Electronic cigarettes produced formaldehyde that affected environment especially in the air, while cigarette butts were found to contain $\mathrm{Hg}$ and $\mathrm{Pb}$ in Persian Gulf Beach. The total of cigarette butts, and $\mathrm{Hg}$ and $\mathrm{Pb}$ associations of butts, were found to vary between 2 and 38 items per square meter and 2.5 and $86.32 \mathrm{ng} / \mathrm{g}$ cigarette butts, as well as 650 and $8630 \mathrm{ng} / \mathrm{g}$ cigarette butts, respectively. The abundance of cigarette butts in marine environment is a source of $\mathrm{Hg}$ and $\mathrm{Pb}$ contamination in coastline area [17].

3.3. Health Complaint of Electronic Cigarettes Smoker. The complaints of electronic cigarettes smokers were irritation in nose, eye, and throat. Nose irritation included itchy nose, uncomfortable smell, and sneezing. Eye irritation included watery eye, sore eye, and reddish eye. Respiration complaints included sore throat, dry throat, cough, and asphyxia. The results are shown in Table 7.

Table 8 showed that cotinine urine was mostly positive (88.0\%). A study in 28 samples showed cotinine urine among electronic cigarettes smokers was 1,880 (mean) compared to cotinine urine among cigarette smokers in 165 samples who were interested in quitting smoking and were assigned low nicotine cigarettes was 3,930 (mean) [18]. The result showed that mostly prevalent complaint was upper airway irritation (dry throat). It was due to vapor smoked from electronic cigarettes. Nose irritation mostly was sneezing while eye irritation was rare. Propylene glycol is known to 
TABLE 8: Cotinine urine of electronic cigarettes smoker in personal vapor community in Surabaya city in 2016.

\begin{tabular}{lc}
\hline Cotinine Urine & Percentage (\%) \\
\hline Negative & 12.0 \\
Positive & 88.0 \\
\hline
\end{tabular}

Source: primary data.

cause upper airway irritation [19]. A study reported that using electronic cigarette had immediate adverse physiologic effects after short-term use which were similar to some effects of tobacco smoking [20]. The health effect of electronic cigarette is influenced by the safety and quality of liquid [21]. It is due to the fact that the solvent of liquid may remain on available surface [22].

Health effect of nicotine and other aerosols that come from electronic cigarettes is not well understood. A research showed that electronic cigarettes aerosol is having a risk for person who has a compromised health condition and limited ventilation. Flavoring availability is for food product not for liquid electronic cigarettes flavoring. There is limited data about the health effect of inhaled flavorings and the synergistic effect from electronic cigarettes contents and environmental contaminants [23]. In Indonesia, there is no regulation of electronic cigarettes yet. While, in 2016, in Great Britain the regulation of electronic cigarettes as a nonprescription medicine started, other countries such as Brazil, Singapore, and Norway have banned the use of electronic cigarettes [5]. Respondent's opinion on policy of electronic cigarette in Indonesia was mostly "do not agree" if there is a policy to restrict electronic cigarette usage. The regulation of electronic cigarettes varies in 33 countries. WHO conducted a survey in 2011 about regulation and availability of electronic cigarettes within their country, 13 reported no availability, 16 reported they were available (nine unregulated, seven with some type of regulation), and four were unsure [24]. An analysis was undertaken of key elements in electronic cigarettes position statements from selected national/international health agencies such as general public health risk assessment and explicit statement that consumers should avoid electronic cigarettes. General public health risk assessment about electronic cigarettes was stated from Non-Smokers' Rights Association (Canada), Campaign for Tobacco Free Kids (USA), Canada Lung Association, and Cancer Society (New Zealand). The explicit statement that consumers should avoid electronic cigarettes was stated from WHO, Scottish Dir Public Health [5]. There are limited data on the effects of recurrent long-term exposures to aerosolized nicotine, flavoring, and propylene glycol. The effects of an aerosol delivery system on the quantity of nicotine consumed by users are unknown. Electronic cigarettes have the potential for significant impact on public health. At this time, data are not sufficient to confirm a long-term benefit for users or a public health benefit for the population at large [25].

The limitation of this research was lack of electronic cigarettes brand distributed in Indonesia, from Indonesia and from other countries as well. Because of it, the determination of electronic cigarettes as samples in this research was not various. Exposure of electronic cigarette related to health complaints was not identified toxicologically. The other chemical measurements in electronic cigarettes were not identified.

\section{Conclusion}

In conclusion, mostly the first time users smoked electronic cigarette was at 2015, smoking frequency of electronic cigarettes was mostly twice a day and three times a day. Health complaints were mostly upper airway irritation with acute effect and mostly cotinine urine was positive. The recommendations are to educate users about hazard of electronic cigarettes due to the regulation of electronic cigarettes not being set yet and to conduct further research to identify chemical agents in electronic cigarettes.

\section{Data Availability}

Data can be accessed by contacting the corresponding author. No data were used to support this study.

\section{Conflicts of Interest}

The authors declare that there are no conflicts of interest regarding the publication of this paper.

\section{Acknowledgments}

The authors acknowledge Universitas Airlangga for funding this research through Annual Budget Activity Plan Universitas Airlangga year 2015. They also thank the enumerator for collecting data and thank respondents who participated in this research.

\section{References}

[1] World Health Organization, "World Health Organization Study Group on Tobacco Regulation. Report on the Scientific Basis of Tobacco Product Regulation : Third Report of a WHO Study Group," 2009.

[2] Ministry of Health, "Bahaya Electronic Cigarettes," 2014, http:// www.depkes.go.id/article/print/20143210002/bahaya-electroniccigarettes.html.

[3] SEARO, "Regulate e-cigarettes To Protect Health," 2013, http:// www.searo.who.int/mediacentre/features/2014/regulate-e-cigarettes-to-protect-health/en/.

[4] Centers for Disease Control and Prevention, "Key Findings: Intentions to smoke cigarettes among never-smoking U.S. middle and high school electronic cigarette users, National Youth Tobacco Survey, 2011-2013," 2013, https://www.ncbi.nlm .nih.gov/pubmed/25143298.

[5] The Union, "Position statement on electronic cigarettes (ecs) or electronic nicotine delivery system (ends)," International Union Against Tuberculosis and Lung Disease, 2013.

[6] W. Schober, K. Szendrei, W. Matzen et al., "Use of electronic cigarettes (e-cigarettes) impairs indoor air quality and increases FeNO levels of e-cigarette consumers,' International Journal of Hygiene and Environmental Health, vol. 217, no. 6, pp. 628-637, 2014. 
[7] T. R. McAuley, P. K. Hopke, J. Zhao, and S. Babaian, "Comparison of the effects of e-cigarette vapor and cigarette smoke on indoor air quality," Inhalation Toxicology, vol. 24, no. 12, pp. 850857, 2012.

[8] ANR, "Electronic smoking devices and secondhand aerosol," Americans for nonsmokers' rights, 2014, http://www.no-smoke .org/.

[9] M. L. Goniewicz, J. Knysak, M. Gawron et al., "Levels of selected carcinogens and toxicants in vapour from electronic cigarettes," Tobacco Control, vol. 23, no. 2, pp. 133-139, 2014.

[10] R. P. Jensen, W. Luo, J. F. Pankow, R. M. Strongin, and D. H. Peyton, "Hidden Formaldehyde in E-Cigarette Aerosols," The New England Journal of Medicine, vol. 372, no. 4, pp. 392-394, 2015.

[11] T. R. Henderson, C. R. Clark, T. C. Marshall, R. L. Hanson, and C. H. Hobbs, "Heat degradation studies of solar heat transfer fluids," Solar Energy, vol. 27, no. 2, pp. 121-128, 1981.

[12] S. Uchiyama, K. Ohta, Y. Inaba, and N. Kunugita, "Determination of carbonyl compounds generated from the E-cigarette using coupled silica cartridges impregnated with hydroquinone and 2,4-dinitrophenylhydrazine, followed by high-performance liquid chromatography," Analytical Sciences, vol. 29, no. 12, pp. 1219-1222, 2013.

[13] E. L. Carmines and C. L. Gaworski, "Toxicological evaluation of glycerin as a cigarette ingredient," Food and Chemical Toxicology, vol. 43, no. 10, pp. 1521-1539, 2005.

[14] M. R. Nimlos, S. J. Blanksby, X. Qian, M. E. Himmel, and D. K. Johnson, "Mechanisms of glycerol dehydration," The Journal of Physical Chemistry A, vol. 110, no. 18, pp. 6145-6156, 2006.

[15] C. Hutzler, M. Paschke, S. Kruschinski, F. Henkler, J. Hahn, and A. Luch, "Chemical hazards present in liquids and vapors of electronic cigarettes," Archives of Toxicology, vol. 88, no. 7, pp. 1295-1308, 2014.

[16] P. Olmedo, W. Goessler, S. Tanda et al., "Metal concentrations in e-cigarette liquid and aerosol samples: the contribution of metallic coils," Environmental Health Perspectives, vol. 126, no. 02, 2018.

[17] S. Dobaradaran, T. C. Schmidt, I. Nabipour et al., "Cigarette butts abundance and association of mercury and lead along the Persian Gulf beach: an initial investigation," Environmental Science and Pollution Research, vol. 25, no. 6, pp. 5465-5473, 2018.

[18] S. S. Hecht, S. G. Carmella, D. Kotandeniya et al., "Evaluation of toxicant and carcinogen metabolites in the urine of e-cigarette users versus cigarette smokers," Nicotine \& Tobacco Research, vol. 17, no. 6, pp. 704-709, 2015.

[19] G. Wieslander, "Experimental exposure to propylene glycol mist in aviation emergency training: acute ocular and respiratory effects," Occupational and Environmental Medicine, vol. 58, no. 10, pp. 649-655, 2001.

[20] C. I. Vardavas, N. Anagnostopoulos, M. Kougias, V. Evangelopoulou, G. N. Connolly, and P. K. Behrakis, "Short-term pulmonary effects of using an electronic cigarette: impact on respiratory flow resistance, impedance, and exhaled nitric oxide," Chest, vol. 141, no. 6, pp. 1400-1406, 2012.

[21] T. Schripp, D. Markewitz, E. Uhde, and T. Salthammer, "Does e-cigarette consumption cause passive vaping?" Indoor Air, vol. 23, no. 1, pp. 25-31, 2013.

[22] T. R. Hammer, K. Fischer, M. Mueller, and D. Hoefer, "Effects of cigarette smoke residues from textiles on fibroblasts, neurocytes and zebrafish embryos and nicotine permeation through human skin," International Journal of Hygiene and Environmental Health, vol. 214, no. 5, pp. 384-391, 2011.

[23] American Industrial Hygiene Association, "White paper: electronic cigarettes in the indoor environment," 2014, https://www .aiha.org/government-affairs/PositionStatements/Electronc\% 20Cig\%20Document_Final.pdf.

[24] CoP to the FCTC, "Electronic nicotine delivery systems, including electronic cigarettes. Report by the Convention Secretariat (FCTC/COP/5/13)," 2012, http://apps.who.int/gb/fctc/PDF/ cop5/FCTC_COP5_13-en.pdf.

[25] P. Callahan-Lyon, "Electronic cigarettes: human health effects," Tobacco Control, vol. 23, no. 2, pp. ii36-ii40, 2014. 


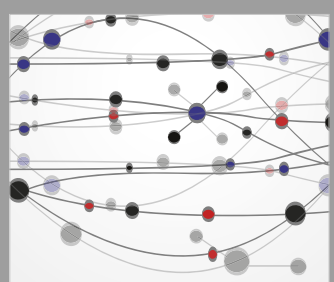

The Scientific World Journal
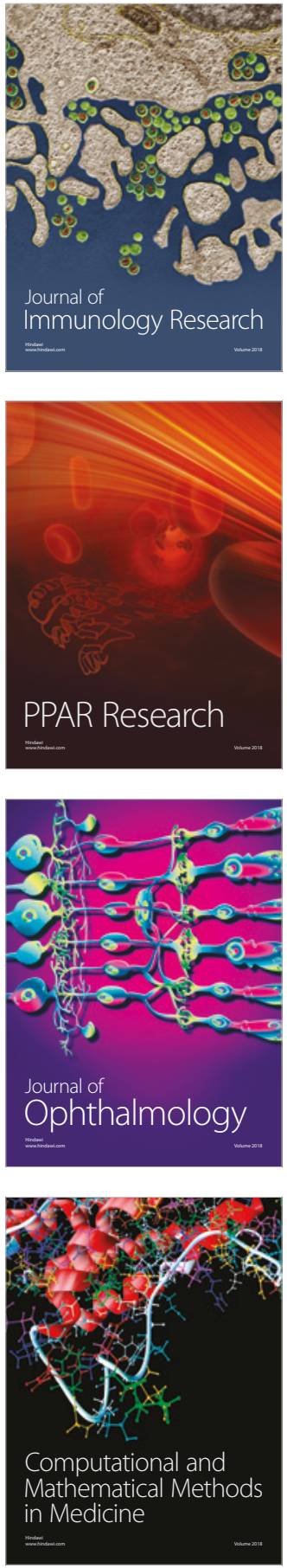

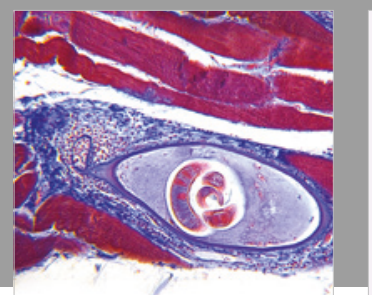

Gastroenterology Research and Practice

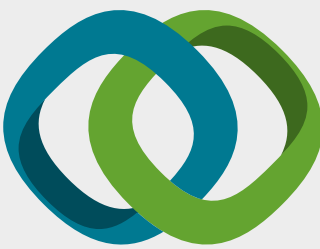

\section{Hindawi}

Submit your manuscripts at

www.hindawi.com
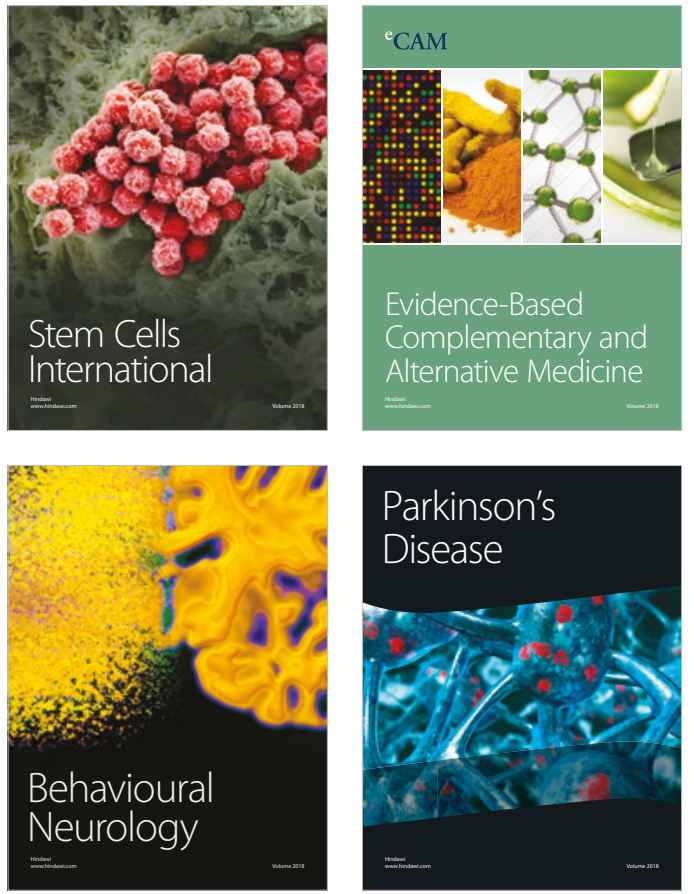

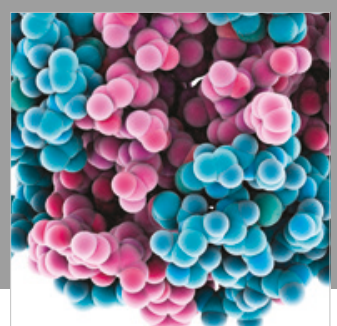

ournal of

Diabetes Research

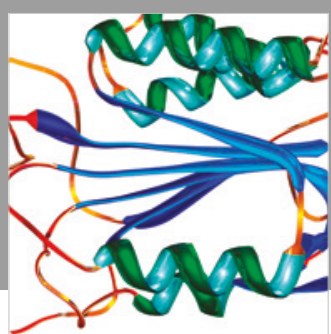

Disease Markers
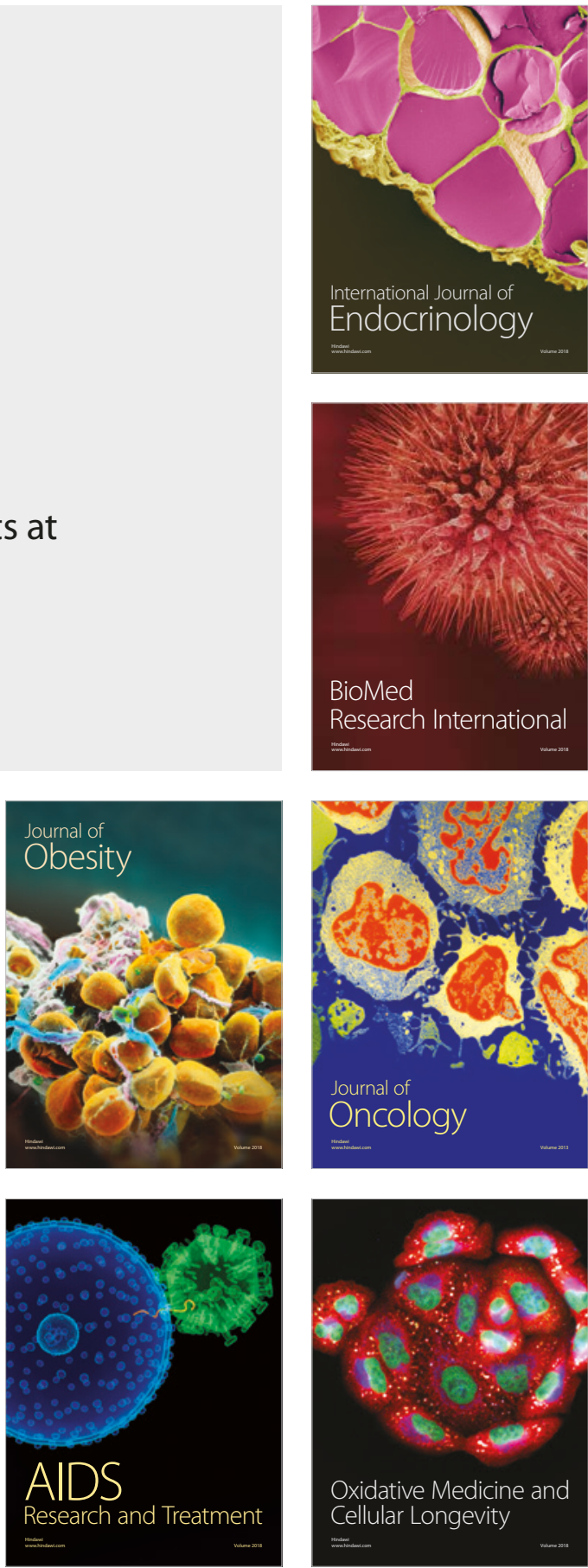